\title{
Polymers Tailored for Controlled (Bio)degradation through End-group and In-chain Functionalization
}

\author{
Joanna Rydz ${ }^{* a, b}$, Marta Musioł ${ }^{\mathrm{a}}$ and Marek Kowalczuk ${ }^{\mathrm{c}}$ \\ ${ }^{a}$ Centre of Polymer and Carbon Materials, Polish Academy of Sciences, Zabrze, Poland; ${ }^{b}$ Institute of \\ Polymers, Bulgarian Academy of Sciences, Sofia, Bulgaria; ${ }^{c}$ Department of Biology, Chemistry and Forensic \\ Science, University of Wolverhampton, Faculty of Science and Engineering, Wolverhampton, UK

\begin{abstract}
Currently, polymers can be created with specific properties that are tailored to a wide range of applications from medical to everyday products as packaging. There are different techniques to prepare novel polymer materials with various architectures and specific groups via a variety of reaction mechanisms of different complexity. End-group modification of polymers is a powerful tool for tailoring polymer properties. The endgroup and in-chain functionalization strategy must be carefully selected based on catalyst, polymerization conditions, and other limitations such as solute solvent interactions or aggregation. The review provide a brief description of the functional moieties and an outline of synthetic strategies used for tailoring the (bio)degradable polymer properties by endgroup and in-chain functionalization.
\end{abstract}

Keywords: polyesters, (bio)degradation, functional moieties, macromolecular architectures, controlled/living polymerization techniques.

\section{INTRODUCTION}

From the perspective of sustainable development, (bio)degradable polymers are considered safe for the environment and are an interesting alternative to conventional polymers. The demand for (bio)degradable polymers that are designed to provide materials for timelimited applications is still growing. Degradation has a significant effect on the properties of polymer materials and therefore the perfect (bio)degradable polymer material should match the mechanical properties and the time of degradation to the needs of the application [1-10]. As the most representative example of environmentally relevant polymeric materials, aliphatic and aliphatic-aromatic polyesters play a predominant role as (bio)degradable, biocompatible and bioresorbable polymers due to the presence of potentially hydrolysable ester linkage $(-\mathrm{C}(\mathrm{O}) \mathrm{O}-)$. However, they often lack good mechanical and physical properties that can be enhanced by functionalization $[11,12]$. Introduction of functional groups such as carboxy ($\mathrm{C}(\mathrm{O}) \mathrm{OH})$, hydroxy $(-\mathrm{OH})$, amino $\left(-\mathrm{NH}_{2}\right)$, bromo $(-\mathrm{Br})$, chloro $(-\mathrm{Cl})$ groups, ketal moiety $\left(\mathrm{R}_{2} \mathrm{C}(\mathrm{OR})_{2}(\mathrm{R} \neq \mathrm{H})\right)$, or carbon-carbon double or triple bonds, causes the aliphatic polyesters are becoming increasingly important in recent years. Other important members of (bio)degradable polymers include polyanhydrides (PAH), poly(ester anhydride)s (PEAH), polyurethanes (PUR), poly(ester urethane)s (PAUR) poly(ortho ester)s (POE), poly(ester amide)s (PEA), poly(ester urea)s (PEU), poly(ester imide)s (PEI), poly(ester amide)s (PEA), polycarbonates (PC) or poly(carbonate urethane)s (PCUR) [13].

*Address correspondence to this author at the Centre of Polymer and Carbon Materials, Polish Academy of Sciences, 34 M. Curie-Skłodowska St., 41-800 Zabrze, Poland, Tel: +48-322-716-077, Fax: +48-322-712-969; E-mail: jrydz@cmpw-pan.edu.pl
The development of new functionalized material is based on the availability of methods providing control over the chemistry and structure of the initiator and diverse range of active end groups in the monomers, allowing to obtain welldefined end-functionalized polymers and block copolymers [14]. Such possibility is provided among others by living polymerization that is a chain polymerization in which chain transfer and chain termination are absent [15]. Thus, in a simple manner using few monomers variety of new materials can be created with significantly different properties by changing the topology of the polymer (linear, crosslinked or branched polymers in particular star-like, hyperbranched polymers, or dendrimers), polymer composition (homo-, random, periodic, block, graft (co)polymers), or position of the functional groups in the polymer chain: end, in-chain, side (end-functional, telechelic, site-specific functional, multifunctional polymers or macromonomers) $[14,16]$ (Fig. $1)$.

Fig. 1. Topologies of functional polymers.

The functional groups may be introduced into the monomers (sometimes in a protected form) before the polymerization or into the polymer chains by postpolymerization modification. (Bio)degradable functional polymers can be synthesized by various direct methods, such as anionic, cationic, free radical or coordination polymerization, as well as in-chain or surface postpolymerization modifications [18].

This review provide a brief description of the functional moieties and an outline of synthetic strategies used for tailoring the (bio)degradable polymer properties by endgroup and in-chain functionalization. 


\section{DEGRADABLE FUNCTIONAL MOIETIES}

Polymer degradation can be caused by mechanical action, heat (thermal degradation), light (photo- or photooxidative degradation), ionizing radiation (radio degradation), chemical agents as water, acid, base (hydrolytic degradation), reactive gases as e.g. oxygen (oxidative or thermo-oxidative degradation) or by fungi, bacteria, yeasts, algae, (biodegradation) and their isolated enzymes (enzymatic degradation) [17]. Type of functional groups in the polymer backbone has the greatest impact on the rate of degradation [18].

Enzymatic and hydrolytic degradations are the key degradation mechanisms considering the biomedical field, since the majority of the bioresorbable polymers contain in the backbone hydrolytically or enzymatically susceptible chemical linkages, such as ester $(-\mathrm{C}(\mathrm{O})-\mathrm{O}-)$, anhydride ($\mathrm{C}(\mathrm{O})-\mathrm{O}-\mathrm{C}(\mathrm{O})-)$, orthoester $\left(-\mathrm{C}(\mathrm{OR})_{3}-\right)$, carbonate $(-\mathrm{O}-\mathrm{C}(\mathrm{O})$ $\mathrm{O}-)$, amide (-C(O)-NH-), urea (-NH-C(O)-NH-), urethane ($\mathrm{NH}-\mathrm{C}(\mathrm{O})-\mathrm{O}$ ) or glycosidic [19] (Fig. 2). The rate of hydrolytic degradation of various polymers is often considerably faster than biodegradation [20].

Fig. 2. Functional moieties of (bio)degradable polymers.

The tendency to hydrolytic degradation depending on the type of functional moieties is as follows: anhydride >ester > orthoester >carbonate > urea > urethane >>ether. Carbonates are known to be hydrolytically more stable than esters due to the two oxygen atoms adjacent to the carbon, which form a pseudo $\pi$ electron system and stabilize the $\mathrm{C}-\mathrm{O}$ bond. This linkage however is less stable then the urethane due to the strong electro-negative effect of oxygen [21].

A different number of the same functional groups inserted into the polymer backbone can affect the rate of hydrolysis. The presence of various functional groups in the copolymer also changes the degradation. Moreover, spacing (steric hindrance) or solubility in water can affect the rate of degradation. Placing alkyl groups $\left(-\mathrm{C}_{\mathrm{n}} \mathrm{H}_{2 \mathrm{n}+1}\right)$, which causes in steric hindrance in the vicinity of groups susceptible to degradation such as an ester moieties, can reduce water attack and hence the degradation. Those groups also reduce the solubility. The neighborhood of the functional groups is also important. Esters with substituents in ortho-position are more readily hydrolyzed under acidic conditions than esters with substituents in meta position $[18,22]$.

The rate of degradation of polymers with ester moiety also significantly differs from each other, taking into consideration steric hindrance or crystallinity. Degradation rate is as follows: poly(lactide-co-glycolide) > polyglycolide $>$ poly $(D L$-lactide $) \quad>$ poly $(L$-lactide $) \quad>$ polycaprolactone $>$ poly(3-hydroxybutrate). Crystallinity is enhanced by: (1) symmetric, regular structure of the polymer which allows packing of the polymer chain in regular and tight way and (2) highly polar side groups that increase the intermolecular forces. Isotactic polymers generally have a higher degree of crystallinity than atactic. Block copolymers have a higher degree of crystallinity than random copolymers from the same units. Thus, the regular polyesters crystallize readily. Even atactic polymer with hydroxy or nitrile (-CN) side groups will crystallize due to polarity [23]. Polylactide (PLA) with hydrophobic pendant methyl group (steric hindrance of $-\mathrm{CH}_{3}$ ) is more protected from the attack of water molecules than polyglycolide (PGA). Amorphous poly $(D L$-lactide) (PDLLA) or copolymer of poly $(L$-lactide) (PLLA) and polyglycolide, wherein the PGA segments are in an amorphous state, degraded more rapidly than partially crystalline PLLA or PGA [24]. When the polylactide content increases, the degradation rate of the copolymer decreases [25]. Also polycaprolactone (PCL) backbone with chemically inert and hydrophobic long methylene segments $\left(\left(-\mathrm{CH}_{2}-\right)_{5}\right)$ between ester linkage is less susceptible to hydrolysis as compared to PLA and PGA. Furthermore, the hydrophobic character of glycolide and lactide copolymers must be adequately modulated in order to prevent the divergence between the rate of degradation of these materials and biological activity. More hydrophilic polymers, such as poly(alkylene tartrate)s, copolymers with gluconic acid or with naturally occurring molecules as lysine, contain functional groups which may enable the conjugation of bioactive molecules [26].

The rate of hydrolysis of ester linkage may also vary depending on the $\mathrm{pH}$ [18]. The hydrolytic chain cleavage of polylactide and polyglycolide increases the concentration of carboxy end-groups and decreases the local $\mathrm{pH}$ with degradation time, which accelerates autocatalysis [5,27]. Azide pendent groups $\left(-\mathrm{N}_{3}\right)$ introduced into aliphatic polyesters by the formation of derivatives with tertiary amines, ammonium salts and poly(ethylene oxide) grafts make the aliphatic polyesters resistant to degradation, including even PLA which is very sensitive to attack by weak nucleophiles [28].

Hydrolysis of polyesters with alkoxyl $\left(-\mathrm{OC}_{\mathrm{n}} \mathrm{H}_{2 \mathrm{n}+1}\right)$ and acyl end-groups $(-(\mathrm{O}) \mathrm{CR})$ does not depend on the type and size of terminal group. It has been found that the hydrolytic stability of ester bonds which are formed in polyester by a monofunctional reagent decreases with a reduction in the hydrocarbon length in the chain of this reagent. The hydrolytic stability of the polyester with relatively longchain end groups depends on the stability of dicarboxylic acid-glycol bond. Resistance to hydrolysis is decreased as follows: neopentyl glycol >ethylene glycol >propylene glycol [29].

During degradation of polycarbonate-based polyurethanes the carbonate linkages are the weakest sites in the polymer backbone. Hence the degradation rate should depend on amount of carbonate linkages compared to urethane. However, there is no linear relationship over the carbonate content. Carbonates can exist in amorphous or crystalline state and can form strong hydrogen bonds with the urethane amines. Therefore H-bonded urethane linkage is more stable than a non-H-bonded one. Degradation initiates the cleavage of the non-H-bonded carbonate and urethane linkages. The highly organized structure of H-bonded hardsegment domains hides potential cleavage sites. Also for phase separated polymers, stability increases if the surfaces is enriched in the phase with higher amount of H-bonded (hard polyurethane) segments compared to the phase that has poor H-bonding as polycarbonates [30]. The degree of phase separation and soft-segment crystallinity have proven to be less important compared to hydrogen bonds between the carbonate and urethane segments. The susceptibility to hydrolysis decreases as follows: non-H-bonded carbonate $>$ non-H-bonded urethane $>\mathrm{H}$-bonded carbonate $>\mathrm{H}$-bonded 
urethane. Water molecules can easily access the H-bonded moieties due to hindrance effect of organized chemical structures included in the H-bonded network and therefore bonded water reduces the attack by free water molecules and hinders the hydrolysis. A higher hard segment content at the surface contributed significantly to an increase in stability [31].

Synthetic polymers of high molar mass usually less readily undergo biodegradation. Exceptions are synthetic aliphatic polyesters which are susceptible to microbial attack regardless of the molar mass. Enzyme binds only substrates that exactly fit into the active site therefore polymer chain must be flexible. Polymers with more rigid chain can slower be biodegradable. Polyesters derived from medium-sized diacids are more easily degraded by microorganism than those derived from the long or short-size diacids. Among the polyesters, PLA is less susceptible to microbial attack because PLA-degrading microorganisms are not widespread in the environment $[32,33]$. Polyamides contain the same amide linkage as polypeptides or proteins; however, due to the high crystallinity and strong chains interactions, the biodegradation rate is so low that they are regarded as nonbiodegradable polymers. Biodegradation can be forced through introduction of side groups such as hydroxy, hydroxyalkyl, carboxy, methyl, benzyl $\left(-\mathrm{CH}_{2} \mathrm{C}_{6} \mathrm{H}_{5}\right)$, formyl $(-\mathrm{CH}(\mathrm{O}))$ or ester moiety. Susceptibility to biodegradation can also increase if the polymer structure possesses unsaturated moieties, straight alkane chains of longer than nine-carbons, lower number of halogen substituents and ortho- or para-substituents on a benzene ring; lack of aromatic units, solubility in water. In addition biodegradation increases under anaerobic conditions while under aerobic conditions is reduced [20Error! Bookmark not defined.]. Aliphatic poly(ester amide)s containing amide and ester linkage or poly(ester urethane)s with long repeating units are more readily biodegraded. Biodegradation rate increases with increasing the content of ester moieties. Biodegradation of polyurethanes depends on the structure: those based on polyethers structure are resistant, whereas those based on polyesters structure are susceptible to biodegradation [33,34]. Also, hydrophobic surface modification of polyurethane-base material with fluorinated end-groups (with one or more fluorine atoms) affects (reduces) biodegradation [19].

Thermo,- photo-, radio-, oxo- and mechanical degradations are important degradation mechanisms considering ageing and pre-programmed lifetime of particular polymeric materials [17].

Polymer structure including elemental constituents, type of bonds (covalent or noncovalent) and degree of unsaturation is important from the standpoint of thermal degradation. Degradation processes involve bond scission that is related to energy expenditure. For example, C-F bond $\left(-\mathrm{CF}_{2} \mathrm{CF}_{2}-\right)$ has a higher thermal stability compared to $\mathrm{C}-\mathrm{H}$ bond $\left(-\mathrm{CH}_{2} \mathrm{CH}_{2}-\right)$ due to higher energy. Thermal degradation is initiated by scission of weak linkages such as ester or carbonate in case of hydrolytic degradation. Tacticity of polymers can also contribute to the thermal stability. Ordered polymers have lower thermal stability than random ones. Increase of the intermolecular forces and the improvement of the thermal stability can be achieved by copolymerization $[23,35]$.
The graft copolymers of chitosan with high content of covalently grafted oligo( $L$-lactide $)$ has proven to be thermally more stable as compared to chitosan. Introduction of flexible units into the rigid polymer chain should disrupt the crystalline structure and might favor the formation of strong hydrogen bonds between grafted chitosan chains thus causing decrease of hydrolytic degradation [36]

For thermo-oxidative degradation, the presence of $\mathrm{C}-\mathrm{H}$ bonds or unsaturated polymer units increases the ability of the formation of peroxy radicals while the saturated polymers structure increases resistant. Also, polymers without hydrogen or with non-reactive methyl or phenyl ($\mathrm{C}_{6} \mathrm{H}_{5}$ ) groups show resistance to oxidation [35]. Functional groups susceptible to oxidative degradation are group with labile hydrogen as benzylic carbon ( $\left.\mathrm{Ph}-\mathrm{C}^{*} \mathrm{HR}\right)$, allylic carbon $\left(\mathrm{CR}_{1}=\mathrm{CH}-\mathrm{C} * \mathrm{HR}_{2}\right)$ and tertiary carbon $\left(\mathrm{CR}_{1}-\mathrm{CR}_{2}-\right.$ $\left.\mathrm{CR}_{3^{-}}\right)$or $\alpha$-positions with respect to heteroatom. Also introduction of ether (-O-), ketone (-C(O)-), amine (-NH-), methylene or ester linkages into the polymer chain such as polyolefin can accelerate oxidative degradation [23,37]. However, the relatively stable to oxidation carbonate linkage in polycarbonate-based polyurethanes lowered the rate of degradation in comparison to the poly(ether urethane)s [38].

Functional moieties susceptible to photo degradation are unsaturated carbon-carbon bonds (e.g. polyene), aromatic rings (e.g. 1,1'-biphenyl-4,4'-diamine), carbonyl $(-\mathrm{C}(\mathrm{O})$-), nitro $\left(-\mathrm{NO}_{2}\right)$ aromatic, amine oxide ( $N$-oxide), alkyl, sulfide salt $\left(\mathrm{S}^{2-}\right)$ moieties or weak $\mathrm{C}-\mathrm{H}$ and $\mathrm{O}-\mathrm{H}$ single bonds as well as $N$-nitrosamines $\left(\mathrm{R}_{2} \mathrm{NN}(\mathrm{O})\right)$ and organochlorines such as $\mathrm{ArCl}[20,37]$.

Radio degradation (radiolysis) breaks chemical bonds; therefore degradation depends on the absorption properties and bond energy. The tertiary carbon bonds in the polymer chain and radiation-absorbing moieties (aromatic rings) are sensitive to radiation attack and form free radicals [39].

Polymer mechanical degradation occurs under the influence of shear forces by random breaking of C-C bonds which results in the formation of terminal C-radicals with possibility to polymer chain scission or braking of $\mathrm{C}-\mathrm{H}$ bonds which results in the formation of C-radicals with possibility to chain branching. The degradation increases with increasing of the applied mechanical stress [40].

\section{POLYMERIZATION TECHNIQUES IN SYNTHESIS OF FUNCTIONAL (BIO)DEGRADABLE POLYESTERS}

The most widely used representatives of the aliphatic polyesters are polymers based on cyclic monomers (cyclic esters or diesters) such as 2-oxetanone ( $\beta$-propiolactone), 4methyloxetan-2-one ( $\beta$-butyrolactone), 3,3-dimethyl-2oxetanone (pivalolactone), tetrahydro- $2 H$-pyran-2-one $(\delta$ valerolactone), 2-oxepanone ( $\varepsilon$-caprolactone), 3,6-dimethyl1,4-dioxane-2,5-dione (lactide, LA) and 1,4-dioxane-2,5dione (glycolide) synthesized in the presence of an initiator and/or a catalyst as well as comonomers [41].

Polyesters such as polylactides and polyhydroxyalkanoates (PHA)s are widely used in biomedical applications, however, the lack of functional moieties along the polymer backbone that are susceptible to the functionalization reactions gives less ability to interact with biological systems [2,42]. A number of routes have 
been used to introduce functional groups into polyesters $[13,43]$. The most common are: (1) synthesis of new functionalized monomers $[44,45]$, (2) chain-end modifications by introducing functional groups to the initiator used in ring-opening polymerization and/or the postpolymerization modification of the polymer hydroxy chain-end [46,47], and (3) copolymerization reaction $[44,48]$. Numerous overviews describe these methods [4953].

The use of a well-defined initiator in controlled polymerizations leads to one $\alpha$-chain-end derived from the initiator and the other $\omega$-chain-end from the propagation species [54]. Chemical modification of the $\omega$-chain-end by the introduction of other polymer chain or small molecules can lead to telechelic polymers with the same functional groups at both the $\alpha$ - and $\omega$-chain ends or to allow postpolymerization reactions [55,56]. Telechelic polymers are synthesized via radical, cationic, and anionic polymerizations including ring-opening polymerization (ROP) [57], step-growth polymerization [58,59], atom transfer radical polymerization (ATRP) [60], reversible addition-fragmentation chain transfer polymerization (RAFT) [61], nitroxide mediated polymerization (NMP) [62] and ring-opening metathesis polymerization (ROMP) [63].

The two main routes to obtain functionalized aliphatic polyesters are step polymerization using mild chemo/enzymatic catalysis and ring-opening polymerization initiated by cationic, anionic, or radical initiators (Fig. 3) $[49,50,64,65]$. Radical ROP is the way of synthesis of polymers with main chains containing heteroatoms [66].

Fig. 3. Main strategies for the synthesis of aliphatic polyesters with functional groups: (I.A) - selfpolycondensation of hydroxy acids or their esters, (I.B) polycondensation of diacids or their esters with diols, (II.A) - ROP of lactones by cationic or anionic catalysis, (II.B) radical ROP of cyclic ketene acetals.

Controlled/living polymerization techniques offer specific methods for end-group functionalization controlled by the active propagating species and the kinetics of the polymerization reaction [67]. By appropriate selection of the functional initiators or macroinitiators as well as addition of a second monomer controlled/living (co)polymerization provides the best opportunity to regulate the properties of target materials by control of the composition, functionality and topology at the molecular level and to obtain tailor-made polymers suitable to the desired applications [68,69] (Fig. 4).

Fig. 4. ROP of $\beta$-butyrolactone and feasibility of copolymerization. Reprinted from Couffin et al. [70].

Diversity of the end groups in synthetic polyesters results from the use of appropriate initiator and/or a catalyst. Many different approaches have been developed in order to obtain functionalized poly(3-hydroxybutyrate)s with the desired end groups [71-74]. The anionic ROP of $\beta$-substituted $\beta$ lactones seems to be a perfect tool for the preparation of analogues of natural aliphatic biopolyesters, PHAs with the desired molecular structure, including the structure of the end groups [75]. Using this approach, with the aid of metalfree anionic initiators, block and random synthetic PHA copolymers can be prepared by anionic ROP of $\beta$ butyrolactone with comonomeric $\beta$-substituted $\beta$-lactones and characterized at the molecular level [76].

Functionalized polyesters can be obtained also by metalfree organocatalytic controlled/living ROP with alcohols as cationic initiators and trifluoromethanesulfonimide $(1,1,1$ trifluoro- $N$-[(trifluoromethyl)sulfonyl]methanesulfonamide, $\mathrm{HNTf}_{2}$ ) as the catalyst (Fig. 5) [56].

Fig. 5. $\mathrm{HNTf}_{2}$-catalyzed ROP of $\varepsilon$-caprolactone ( $\varepsilon$-CL), 1,4dioxepan-5-one (DXO), and $D L$-lactide (rac-LA) using 3phenylpropan-1-ol (PPAL), propargyl alcohol (prop-2-yn-1ol, PAL), 6-azidohexan-1-ol (AHAL), N-(2hydroxyethyl)maleimide (1-(2-Hydroxyethyl)- $1 H$-pyrrole2,5-dione, HEMI), hex-5-en-1-ol (HEAL), 2-hydroxyethyl methacrylate (2-propenoic acid, 2-methyl-, 2-hydroxyethyl ester, HEMA), and poly(ethylene glycol) methyl ether $(\alpha-$ hydro- $\omega$-methoxypoly(oxyethylene), MPEG). Reprinted from Makiguchi et al. [56].

Polyesters containing functional side-chain moieties, such as pendant primary hydroxy groups, can be prepared from alternating ROP of oxetanes with carboxylic acid anhydrides, and of 3,3-bisoxetanes with dicarboxylic acids or by ROP of $\alpha, \alpha^{\prime}, \beta$-trisubstituted $\beta$-lactones $[26,77,78]$. The presence of the carboxy side-chain groups in poly(malic acid) (PMLA) backbone allows to obtain range of materials of different physicochemical properties, either by direct copolymerization of monomers having different ester side groups or by postmodification of PMLA [26].

Ring-opening metathesis polymerization (ROMP) is good method to synthesize polymers with functional groups only at one of the chain-end (mono-end functional polymers) as it is one of the most functional group tolerant polymerization methods known. Usually, the ROMP leads to the nondegradable polymers. In order to synthesize functional homopolymer with degradable backbone using ROMP, strained cyclic or bicyclic monomers that can undergo polymerization are required, such as for example unsaturated lactones or cyclic carbonates. So the monomer must contain core (linear polymer backbone) functionality giving rise to polymer structure that can undergo degradation (an acid or enzyme labile functionality such as ester or amide moieties) and with desired monomer or polymer functionality needed to enable polymer diversification [79]. ROMP of unsaturated $\varepsilon$-caprolactone (6,7-dihydro-2(3H)oxepinone, DHO2) initiated by Schrock's Mo-based catalyst, allows to obtain unsaturated degradable polyesters [63Error! Bookmark not defined.]. ROMP of unsaturated lactone or cyclic carbonate gives carboxy or formyl endfunctionalized polymers [80]. Hetero-end functional polymers, i.e. polymers with different functional groups at each chain end can be obtained by combining sacrificial synthesis with the vinyl lactone termination technique [81].

The copolymerization is a good method of tailoring macromolecular architecture to achieve the desired functionality. Copolymers are one of the most important polymeric materials due to the presence of two or more chemically different polymeric building blocks with specific properties. Creation of various different architectures, such as block, star and graft copolymers results in microphase separation and formation of different domain structures 
(crystalline, amorphous, rubbery or glassy) which acts as physical crosslinks $[82,83]$.

The ring-opening copolymerization of cyclic esters or diesters with functional comonomers offers a good method for the functionalization of the polymer backbone. Precursor studies have been developed by Vert. Various protected functional lactones are used in ring-opening copolymerization with lactide [84]. Kricheldorf et al. [85] for the first time reported a novel approach to the preparation of functional polylactides by the polymerization of $L$-lactic acid $O$-carboxyanhydride ((5S)-5-methyl-1,3-dioxolane-2,4dione, $L$-Lac-OCA) monomer using a variety of initiators, such as pyridine, $N, N$-diethylethanamine, $\mathrm{KOtBu}$ (potassium 2-methylpropan-2-olate), or $\operatorname{Ti}(\mathrm{O}-\mathrm{Bu})_{4}($ titanium $(4+)$ tetra(1butanolate)). This reactive monomer is also investigated by many other groups. Tailored polymers derived from well defined poly(hydroxy acid)s can be obtained using different catalytic approaches: metal-free synthetic methods with nucleophilic (protic) [86,87], cationic as well as enzymatic [88] initiators or alkoxy rare earth compounds [89] and with potential applications in drug and gene delivery systems [9092].

Multifunctional brush and block graft copolymers consisting of polymer chains covalently attached to a core can be prepared through "grafting from", "grafting through," and "grafting onto". Polyesters, atactic or isotactic poly(3hydroxybutanoate) macromonomers, functionalized with methacrylate end-groups can be copolymerized in a one-step procedure with several methacrylates via grafting through by ATRP $[12,93]$. A water-soluble brush copolymers composed of synthetic poly(3-hydroxybutanoate) (PHB) and $\alpha$-hydro$\omega$-hydroxypoly(oxyethylene) (PEG) brushes are prepared applying a three-step procedure, including ATRP processes $[12,94]$. Star polymers consist of linear chains covalently attached to a central core and have a lower density of functional group when compared to dendrimer or dendronized polymers [55]. Telechelic star polymers are molecules made of polymer with one chain-end chemically bonded to the center of the star while the other chain-end is functionalized [95]. Star-shaped polyesters with pyrenyl, polycyclic aromatic hydrocarbon (lipophilic) end- group or hydroxy (hydrophilic) end-group can be synthesized by ROP of LA or $\varepsilon$-CL co-initiated with corresponding alcohol and polyols or 3-isocyanatopropyl(trimethoxy)silane to obtain (bio)degradable polymers with good mechanical properties $[96,97]$.

Functionalized polymers could also be obtained by biosynthesis. Various PHAs with side chains containing functional moieties (e.g., carbon-carbon double or triple bonds, ketone or epoxide moieties, acetyloxy (-O-C(O)$\mathrm{CH}_{3}$ ), aromatic or halogen groups) can be obtained by advanced in vivo production strategy. The biosynthesis of functional PHAs which gives different composition units depend not only on the carbon source and type of microorganisms, but also on the dilution rate, the carbon to nitrogen ratio, time and temperature $[98,99]$. When the introduction of functional moieties during biosynthesis is impossible or the presence of functional groups in the PHAs provides sites for subsequent chemical modification the postfunctionalization is used to obtain functionalized PHAs [100,101]. Basic methods to functionalize PHAs are: (i) chemical in-chain modification of biosynthetic PHAs through complete hydrolysis of PHA backbone to chiral monomer or (ii) degradation to short-chain-length PHA followed by the synthesis of block copolymers or chemical side-chain modification through reactions of medium-chainlength PHAs having unsaturated side chains such as crosslinking, epoxidation, conversion of double bonds to diols or carboxy moieties [102-105]. Biosynthetic PHAs are also used to obtain poly(ester urethane)s by linking PHA blocks with diisocyanate coupling agents $[106,107]$.

\section{STEP-GROWTH POLYMERIZATIONS IN SYNTHESIS OF FUNCTIONAL (BIO)DEGRADABLE POLYMERS}

Polycondensation can be performed by various polymerization techniques such as melt, solid-state, interfacial and emulsion polymerization. A specific functionality can be introduced through these method using functionalized monomers or functionalized initiators [108]. Functionalization of PLA may be used for further preparation of various polymers. Direct melt polycondensation of lactic acid (2-hydroxypropanoic acid) and citric acid (2-hydroxypropane-1,2,3-tricarboxylic acid) leads to carboxy-functionalized PLA (Fig. 6). The structures involving citryl units into the polymer and subsequent branching are formed at low concentration of citric acid in reaction mixtures [109].

Fig. 6. Structure of carboxy-functionalized PLA.

Synthesis of biodegradable aliphatic polyesters by two-stage melt polycondensation has been investigated under different conditions. Poly(ethylene succinate), poly(propylene succinate) and poly(butylene succinate) can be obtained using appropriate diols and succinic acid (butanedioic acid). The rate constant of esterification reaction is much larger in comparison to the transesterification reaction which leads to very high values of the hydroxy end-groups compared to corresponding carboxy end-groups. Also changes in the amount of inactive end groups at different reaction temperatures are observed [110]. Polycondensation of sebacic acid (decanedioic acid) and glycerol (propane-1,2,3triol) leads to poly(glycerol sebacate). During this reaction functionalized polymer is obtained with secondary hydroxy groups. Some of them remain free and some are transformed to ester moieties that link polymer chains [111]. Aliphatic polyesters with pendant hydroxy groups can be prepared by lipase-catalyzed polycondensation between triols and diester (divinyl adipate) and analyzed by MALDI-TOF mass spectrometry. The results showed that the polyester chains are terminated with various groups: vinylic $\left(-\mathrm{CH}=\mathrm{CH}_{2}\right)$, hydroxy, vinylic and hydroxy, vinylic and carboxy as well as hydroxy and carboxy groups [112]. Interfacial polycondensation of 1,6-hexanediol diesters of $L$ - and $D$ alanine with sebacoyl chloride (decanedioyl dichloride) can be used to obtain poly(ester amide)s with different alanine contents [113]. Selectivity of the specific catalysts in the presence of primary alcohols have a significant impact on the synthesis of linear polyesters through one step polycondensation of monomers heaving secondary pendant hydroxy groups. Enzymatic and Lewis catalysis can be used to conduct the reaction of the acid functionality with primary alcohols. This reaction is not going with lateral secondary alcohols allowing to avoid cross-linking and gelation. 
Polycondensation which is enzymatically catalyzed allows one-step synthesis of hydroxy pendant polyesters using the polyol monomer from renewable resources [114]. Glycerol (propane-1,2,3-triol), butane-1,2,4-triol and hexane-1,2,6triol can be copolymerized with divinyl esters to linear hydroxy- substituted polyesters by using Novozyme-435 lipase and Candida antartica lipase B [112,115]. Because in the polymer the pendant hydroxy groups are mainly secondary, the reaction is regioselective. Also Novozyme435 can be used for copolymerization of glycerol with adipic acid and 1,8-octanetriol receiving a few intermolecular crosslinks in addition to hydroxy pendant groups [116]. Optical active poly(ester imide)s (PEI)s with various amino acid residues in the main chain can be obtained by polycondensation of $N, N^{\prime}$-(pyromellitoyl)-bis- $L$-tyrosine dimethyl ester as a diphenolic monomer and two chiral trimellitic anhydride-derived diacid monomers containing $S$ valine and $L$-methionine. The degradation of obtained PEIs under the soil condition showed that these materials are biologically active and biodegradable [117]. Poly(ester amide)s (PEA)s can be obtained from condensation reactions of $\alpha, \omega$-aminoalcohols with acid anhydrides or dicarboxylic acid derivatives. If the monomer contains $\alpha$-amino acid or carbohydrate units or even one unsaturated monomer it is easy to obtain functionalized PEAs [118]. Functional poly(ester anhydride)s (PEAH)s based on succinic acid can be obtained by the three-step synthesis. The first step involved melt condensation of allyl glycidyl ether (2[(allyloxy)methyl]oxiran) with succinic acid, the second conversion of carbonyl moiety of the macromer to mixed anhydride moieties, and the third - melt polycondensation of ester anhydride prepolymer. ${ }^{1} \mathrm{H}$ and ${ }^{13} \mathrm{C}$ NMR spectra showed signals attributed to methylene and methine protons or carbon atoms in allyl moieties $\left(\mathrm{H}_{2} \mathrm{C}=\mathrm{CH}-\mathrm{CH}_{2} \mathrm{R}\right)$ which confirmed that allyl moieties are presented in side chain of PEAHs [119].

Polyurethanes (PUR)s are widely use polymers in many applications from elastic fibers through elastomers to different foams. This group of polymers is mainly obtained by polyaddition. The main functional moieties susceptible to hydrolytic or enzymatic degradation in the (bio)degradable PURs and poly(urethane urea)s PURUs backbones are ester, urethane, urea, and amide. Also oxidative degradation by the ether linkages (-C-O-C-) can be promoted when polyether polyols such as poly(ethylene oxide) (PEO) are used in PUR formulations [120].

Poly(amido amine)s (PAMAM)s are highly functional polymers which offers a variety of strategic properties, such as biocompatibility or biodegradability. The stepwise polyaddition of primary or secondary aliphatic amines to bis(acrylamide)s is used for the preparation of PAMAMs. The backbone of PAMAM contains a lot of tertiary amino and amido groups which gives significant possibilities of further chemical functionalization. $\mathrm{pH}$-sensitive PAMAM can be obtained by inclusion of the ketals and acetals into the polymer backbone. To introduce desired functionalities it need only to vary the monomers used for the polymerization. Also when useing the oligoamines and disulfide-containing cystamine bisacrylamide in the polyaddition the reducible disulfide bonds are introduce into the backbone of linear PAMAM. This method increases the biocompatibility of the polymer [121-123]. PAMAMs with amine or acrylamide terminal groups can be obtained by polyaddition from difunctional macromers. Appropriate selection of the diamine and bisacrylamide comonomers allows controlled rate of macromer degradation. Higher-functionality crosslinkers, and hydroxy or carboxy groups can be easily incorporated into the macromere [124]. Heterotelechelic PEOs are obtained by living anionic polyaddition of ethylene oxide (oxirane) initiated by an alkaline metal alkoxide. The functional group from the initiator became the end group of the chains to be used further for the anchoring of the pilot molecules [125]. $D$-Glucaro-1,4:6,3-dilactone (bicyclic dilactone of $D$-glucaric acid) with $p$-xylylenediamine can be used to obtained poly( $p$-xylylene- $D$-glucaramide $)$ by polyaddition reaction. This polyamine has many pendant hydroxy groups [126] (Fig. 7).

Fig. 7. Synthesis of poly( $p$-xylylene- $D$-glucaramide): (a) $D$-glucose, (b) - $D$-glucaric acid, (c) $-D$-glucaro-1,4:6,3dilactone, (d) $-p$-xylylenediamine, (e) $-\operatorname{poly}(p$-xylylene- $D$ glucaramide).

Atom transfer radical polyaddition reactions of 1,2-bis(4vinylbenzyloxy)ethane, styrene monomer, with 2-(2-bromo2-methylpropanoyl)oxyethyl 2-bromo-2-methylpropanoate or 2-[2-(2-bromo-2methylpropanoyl)oxyethyldisulfanyl]ethyl 2-bromo-2methylpropanoate, difunctional (bio)degradable ATRP initiators leads to new linear functionalized polyesters with pendent bromides or disulfide groups in the polyester main chain [127]. Photoresponsive poly( $\beta$-amino ester)s (PbAE)s can be prepared through polyaddition of (2-nitro-1,3phenylene) bis(methylene) diacrylate and a bifunctional amine. The polymers can degrade within several minutes upon UV irradiation due to the fact that they have a nitrobenzene moiety in each repeating unit [128]. The degradation rate of PbAEs with pendant primary amines depends on their side-chain structures. Also $\mathrm{pH}$ value has a significant impact on the degradation. Lowering of $\mathrm{pH}$ causes in decrease of the degradation rate. Mechanism of degradation involves intramolecular/intermolecular amidation and hydrolysis [129].

\section{CONCLUSIONS}

The contemporary synthetic strategies used in tailoring the (bio)degradable polymer properties by the end-group and in-chain functionalization presented in this review demonstrate the importance of the relation between their subtle molecular structure, properties and function. When the development of (bio)degradable polymers is in its infancy the most crucial features are concentrated on the effect of macromolecular architecture, new monomer systems, polymerization mechanisms and different polymerization techniques on final (bio)degradable properties. Significant efforts have been directed towards the type of functional moieties and their influence on the degradation manner. Environmental impact and in particular (bio)degradation in view of the potential applications in various fields need particular emphasis. The diverse applications of biodegradable polymers require specific characterization and optimization of the material properties, its preparation, processing and recycling. Pulling these different elements together should help to design novel biodegradable 
polymeric materials and to avoid failures of the commercial products manufactured from them.

\section{REFERENCES}

[1] Middleton, J.C.; Tipton, A.J. Synthetic biodegradable polymers as orthopedic devices. Biomaterials, 2000, 21(23), 2335-2346.

[2] Rydz, J.; Zawidlak-Węgrzyńska, B.; Christova D. Degradable polymers. In: Encyclopedia of biomedical polymers and polymeric biomaterials; Mishra, M.K., Ed.; CRC Press: Boca Raton, 2015; pp. 2327-2349.

[3] Sikorska, W.; Dacko, P.; Sobota, M.; Rydz, J.; Musioł, M.; Kowalczuk, M. Degradation study of polymers from renewable resources and their compositions in industrial composting pile. Macromol. Symp., 2008, 272, 132-135.

[4] Musioł, M.T.; Rydz, J,; Sikorska, W.J.; Rychter, P.R.; Kowalczuk, M.M. A preliminary study of the degradation of selected commercial packaging materials in compost and aqueous environments. Pol. J. Chem. Tech., 2011, 13, 55-57.

[5] Rydz, J.; Adamus, G.; Wolna-Stypka, K.; Marcinkowski, A.; Misiurska-Marczak, M.; Kowalczuk, MM. Degradation of polylactide in paraffin and selected protic media. Polym. Degrad. Stab., 2013, 98, 316-324.

[6] Rydz, J.; Wolna-Stypka, K.; Adamus, G.; Janeczek, H.; Musioł, M.; Sobota, M.; Marcinkowski, A.; Kržan, A.; Kowalczuk, M. Forensic engineering of advanced polymeric materials. Part $1-$ Degradation studies of polylactide blends with atactic poly[(R,S)-3hydroxybutyrate] in paraffin. Chem. Biochem. Eng. Q., 2015, 29, 247-259.

[7] Rydz, J.; Wolna-Stypka, K.; Musioł, M.; Szeluga, U.; Janeczek, H.; Kowalczuk, M. Further evidence of polylactide degradation in paraffin and in selected protic media. A thermal analysis of eroded polylactide films, Polym. Degrad. Stab. 2013, 98(8), 1450-1457.

[8] Sikorska, W.; Richert, J.; Rydz, J.; Musioł, M.; Adamus, G.; Janeczek, H.; Kowalczuk, M. Degradability studies of poly(Llactide) after multi-reprocessing experiments in extruder. Polym. Degrad. Stabil., 2012, 97, 1891-7.

[9] Sikorska, W.; Musiol, M.; Nowak, B.; Pajak, J.; Labuzek, S.; Kowalczuk, M.; Adamus G. Degradability of polylactide and its blend with poly[(R,S)-3-hydroxybutyrate] in industrial composting and compost extract. Int. Biodeter. Biodegr., 2015, 101, 32-41.

[10] Musiol, M.; Sikorska, W.; Kowalczuk, M.; Adamus G. The development of sustainable bioplastics for new applications in packaging industry. Int. J. Environ. Agric. Res., 2016, 2, 117-124.

[11] Vert, M. Aliphatic polyesters: great degradable polymers that cannot do everything. Biomacromolecules, 2005, 6(2), 538-46.

[12] Rydz, J.; Sikorska, W.; Kyulavska, M.; Christova, D. Polyesterbased (bio)degradable polymers as environmentally friendly materials for sustainable development. Int. J. Mol. Sci., 2015, 16(1), 564-596.

[13] Tian, H.; Tang, Z.; Zhuang, X.; Chen, X.; Jing X. Biodegradable synthetic polymers: Preparation, functionalization and biomedical application. Prog. Polym. Sci., 2012, 37, 237-280.

[14] Patten, T.E.; Matyjaszewski, K. Atom transfer radical polymerization and the synthesis of polymeric materials. $A d v$. Mater., 1998, 10, 901-915.

[15] Jenkins, A.D.; Jones, R.G.; Moad, G. Terminology for reversibledeactivation radical polymerization previously called "controlled" radical or "living" radical polymerization (IUPAC Recommendations 2010). Pure Appl. Chem., 2010, 82(2), 483-491.

[16] Schulz, D.N.; Patil, A.O. Functional Polymers: An Overview. In: Functional polymers. Modern synthetic methods and novel structures; Patil, A.O.; Schulz, D.N.; Novak, B.M., Eds; ACS Symp. Ser. 704. ACS: Washington, 1998; Chapter 1, pp. 1-14.

[17] Yousif, E.; Haddad, R. Photodegradation and photostabilization of polymers, especially polystyrene: review. SpringerPlus, 2013, 2, 398, 32 pages.

[18] Göpferich, A. Mechanisms of polymer degradation and elimination. In: Handbook of biodegradable polymers; Domb, A.J.; Kost, J.; Wiseman, D., Eds.; Harwood Academic: Amsterdam, 1997; pp. 451-471.

[19] Azevedo, H.S.; Reis, R.L. Understanding the Enzymatic degradation of biodegradable polymers and strategies to control their degradation rate. In: Biodegradable systems in tissue engineering and regenerative medicine; Reis, R.L., San Roman, J., Eds.; CRC Press, Taylor \& Francis Group: Boca Raton, FL, 2005; pp. 177-201.
[20] Shonnard, D.; Lindner, A.; Nguyen, N.; Ramachandran, P.A.; Fichana, D.; Hesketh, R.; Stewart Slater, C.; Engler, R. Green engineering-integration of green chemistry, pollution prevention, and risk-based considerations. In :Handbook of industrial chemistry and biotechnology; Kent, J.A. Ed.; Springer Science \& Business Media: New York, 2012; Vol. 1, pp. 155-199.

[21] Tang, YW.; Labow, RS.; Revenko, I.; Santerre, JP. Influence of surface morphology and chemistry on the enzyme catalyzed biodegradation of polycarbonate-urethanes. J. Biomater. Sci. Polym. Ed., 2002, 13(4), 463-483.

[22] Wicks Jr., Z.W.; Jones, F.N.; Pappas, S.P.; Wicks, D.A. Exterior durability. In: Organic coatings: science and technology; Wicks Jr., Z.W.; Jones, F.N.; Pappas, S.P.; Wicks, D.A., Eds.; John Wiley \& Sons: Hoboken, NJ, 2007; pp. 97-120.

[23] Beyler, C.L.; Hirschler, M.M. Thermal decomposition of polymers. In: SFPE Handbook of fire protection engineering; Di Nenno, P.J. Ed.; NFPA: Quincy, MA, 2001; $3^{\text {rd }}$ ed., pp. 110-131.

[24] Chen, Q.; Thouas G. Biomaterials: A Basic Introduction; CRC Press, 2014.

[25] Miller, R.A.; Brady, J.M.; Cutright, D.E. Degradation rates of oral resorbable implants (polylactates and polyglycolates): Rate modification with changes in PLA/PGA copolymer ratios. $J$. Biomed. Mat. Res., 1977, 11, 711-719.

[26] Cerbai, B.; Solaro, R.; Chiellini, E. Synthesis and characterization of functional polyesters tailored for biomedical applications. $J$. Polym. Sci. Part A: Polym. Chem., 2008, 46, 2459-2476.

[27] Siparsky, G.L.; Voorhees K.J.; Miao F. Hydrolysis of polylactic acid (PLA) and polycaprolactone (PCL) in aqueous acetonitrile solutions: autocatalysis. J. Polym. Environ., 1988, 6, 31-41.

[28] Riva, R.; Schmeits, S.; Stoffelbach, F.; Jérôme, C.; Jérôme, R.; Lecomte P. Combination of ring-opening polymerization and "click" chemistry towards functionalization of aliphatic polyesters. Chem. Commun., 2005, 42, 5334-5336.

[29] Bulai, A.Kh.; Slonim, I.Ya.; Urman, Ya.G.; Barshtein, R.S.; Gorbunova, V.G.; Sorokina, I.A. Study of hydrolytic degradation of polyester plasticizers by NMR ${ }^{1 \mathrm{H}}$ and ${ }^{13 \mathrm{C}}$ methods. Polym. Sci. USSR., 1978, 20(9), 2338-2347.

[30] Tang, Y.W.; Labow, R.S.; Santerre, J.P. Enzyme-induced biodegradation of polycarbonate polyurethanes: dependence on hard-segment concentration. J. Biomed. Mater. Res., 2001, 56(4), 516-528.

[31] Tang, Y.W.; Labow, R.S.; Santerre, J.P. Enzyme-induced biodegradation of polycarbonate-polyurethanes: dependence on hard-segment chemistry. J. Biomed. Mater. Res., 2001, 57(4), 597611.

[32] Ren, J. Standard and Test Methods. In: Biodegradable poly(lactic acid): synthesis, modification, processing and applications; Ren, J., Ed.; Springer: Berlin Heidelberg, 2010; pp. 273-296.

[33] Mitrus, M.; Wojtowicz, A.; Moscicki. L. Biodegradable polymers and their practical utility. In: Thermoplastic starch: a green material for various industries; Janssen, L.; Moscicki, L., Eds; John Wiley \& Sons: Weinheim, Germany, 2009; Chapter 1, pp. 134.

[34] Vroman, I.; Tighzert, L. Biodegradable polymers. Materials, 2009, 2, 307-344.

[35] Ray, S.; Cooney, R.P. Termal degradation of polymer and polymer composities. In: Handbook of environmental degradation of materials; Kutz, M., Ed.; Elsevier: Oxford, Great Britain, 2012; $2^{\text {nd }}$ ed., pp. 213-242.

[36] Luckachan, G.E.; Pillai, C.K.S. Chitosan/oligo L-lactide graft copolymers: effect of hydrophobic side chains on the physicochemical properties and biodegradability. Carbohydr. Polym., 2006, 24, 254-266.

[37] Blessy, M.; Patel, R.D.; Prajapati, P.N.; Agrawal, Y.K. Development of forced degradation and stability indicating studies of drugs - A review. J. Pharm. Anal., 2014, 4(3), 159-165.

[38] Mathur, A.B.; Collier, T.O.; Kao, W.J.; Wiggins, M.; Schubert, M.A.; Hiltner, A.; Anderson, J.M. In vivo biocompatibility and biostability of modified polyurethanes. J. Biomed. Mater. Res., 1997, 36(2), 246-257.

[39] Delre, L.C.; Miller, R.W. Characterization. of. weathering. and. radiation susceptibility. In: Characterization and failure analysis of plastics. Lampman, S. ASM International: Ohio, USA, 2003; pp.153-158.

[40] Degradation behaviour of polymer blends and thermal treatment of polymer waste. In: Handbook of polymer blends and composites Kulshreshtha, A.K.; Vasile, C., Eds; Smithers Rapra Publishing: Shawbury, UK, 2003; Vol. 3B, pp. 561-582. 
[41] Hedir, G.G.; Bell, C.A.; Ieong, N.S.; Chapman, E.; Collins, I.R.; O'Reilly, R.K.; Dove, A. P. Functional degradable polymers by xanthate-mediated polymerization. Macromolecules, 2014, 47(9), 2847-2852.

[42] Riva, R.; Lussis, P.; Lenoir, S.; Jérôme, C.; Jérôme, R.; Lecomte, $\mathrm{P}$. Contribution of "click chemistry" to the synthesis of antimicrobial aliphatic copolyester. Polymer, 2008, 49(8), 20232028.

[43] Heiny, M.; Wurth, J.J.; Shastri, V.P. Progress in functionalized biodegradable polyesters. In Natural and synthetic biomedical polymers; Kumbar, S.; Laurencin, C.; Deng, M., Eds.; Elsevier: Amsterdam, The Netherlands, 2014; pp. 167-180.

[44] Hedir, G.G.; Bell, C.A.; O’Reilly, R.K.; Dove, A.P. Functional degradable polymers by radical ring-opening copolymerization of MDO and vinyl bromobutanoate: synthesis, degradability and postpolymerization modification. Biomacromolecules, 2015, 16(7), 2049-2058.

[45] Brown, A.H.; Sheares, V.V. Amorphous unsaturated aliphatic polyesters derived from dicarboxylic monomers synthesized by Diels-Alder chemistry. Macromolecules, 2007, 40, 4848-4853.

[46] Arkin, Z.G.; Rydz, J.; Adamus, G.; Kowalczuk, M. Water-soluble L-alanine and related oligopeptide conjugates with poly[(R,S)-3hydroxybutanoic acid] oligomers. Synthesis and structural studies by means of electrospray ionization multistage mass spectrometry. J. Biomater. Sci. Polym. Edn., 2001, 12, 297-305.

[47] Wilson, J.A.; Hopkins, S.A.; Wright, P.M.; Dove, A.P. Synthesis and postpolymerization modification of one-pot $\omega$ pentadecalactone block-like copolymers. Biomacromolecules, 2015, 16(10), 3191-200.

[48] Heiny, M.; Shastri, V.P. Cyclic comonomers for the synthesis of carboxylic acid and amine functionalized poly(l-lactic acid). Molecules, 2015, 20, 4764-4779.

[49] Jérôme, C.; Lecomte, P. Recent advances in the synthesis of aliphatic polyesters by ring-opening polymerization. Adv. Drug Delivery Rev., 2008, 60, 1056-1076.

[50] Williams, C.K. Synthesis of functionalized biodegradable polyesters. Chem. Soc. Rev., 2007, 36(10), 1573-80.

[51] Pounder R. J.; Dove A. P. Towards poly(ester) nanoparticles: recent advances in the synthesis of functional poly(ester)s by ringopening polymerization. Polym. Chem., 2010, 1, 260

[52] Hvilsted, S. Facile design of biomaterials by 'click' chemistry. Polym. Int., 2012, 61, 485-494.

[53] Sisson, A.L.; Ekinci, D.; Lendlein, A. The contemporary role of $\varepsilon$ caprolactone chemistry to create advanced polymer architectures. Polymer, 2013, 54(17), 4333-4350.

[54] Schubert, U.S.; Heller, M. Metallo-supramolecular initiators for the preparation of novel functional architectures. Chem. Eur. J., 2001, 7(24), 5252-5259.

[55] Iha, R.K.; Wooley, K.L.; Nyström, A.M.; Burke, D.J. ; Kade, M.J.; Hawker, C.J. Applications of orthogonal, "click" chemistries in the synthesis of functional soft materials. Chem Rev., 2009, 109(11), 5620-5686.

[56] Makiguchi, K.; Kikuchi, S.; Satoh, T.; Kakuchi, T. Synthesis of block and end-functionalized polyesters by triflimide-catalyzed ring-opening polymerization of $\varepsilon$-caprolactone, 1,5-dioxepan-2one, and rac-lactide. J. Polym. Sci. Part A: Polym. Chem., 2013, 51, 2455-2463.

[57] Saito, T.; Aizawa, Y.; Tajima, K.; Isono, T.; Satoh, T. Organophosphate-catalyzed bulk ring-opening polymerization as an environmentally benign route leading to block copolyesters, end-functionalized polyesters, and polyester-based polyurethane. Polym. Chem., 2015, 6, 4374-4384.

[58] Hiltunen, K.; Härkönen, M.; Seppälä, J.V.; Väänänen, T. Synthesis and characterization of lactic acid based telechelic prepolymers. Macromolecules, 1996, 29(27), 8677-8682.

[59] Yagci, Y.; Nuyken, O.; Graubner, V.-M. Telechelic polymers. In: Encyclopedia of polymer science and technology.; Kroschwitz, J.I., Ed.; Wiley and Sons: New York, 2005; $3^{\text {rd }}$ ed., Vol. 12, pp. 57-130.

[60] Okcua, S.S.; Durmazb, Y.Y.; Yagci, Y. Synthesis and characterization of telechelic block co-polymers by combination of atom transfer radical polymerization and click chemistry processes. Des. Monomers Polym., 2010, 13, 459-472.

[61] You, Y.; Hong, C.; Wang, W.; Lu W.; Pan, C. Preparation and characterization of thermally responsive and biodegradable block copolymer comprised of PNIPAAM and PLA by combination of ROP and RAFT methods. Macromolecules, 2004, 37(26), 97619767.
[62] Clement, B.; Trimaille, T.; Alluin, O.; Gigmes, D.; Mabrouk, K.; Feron, F.; Decherchi, P.; Marqueste T.; Bertin, D. Convenient access to biocompatible block copolymers from SG1-based aliphatic polyester macro-alkoxyamines. Biomacromolecules, 2009, 10, 1436-1445.

[63] Lou, C.; Detrembleur, X.; Lecomte, P.; Jérôme, R. Novel unsaturated $\varepsilon$-caprolactone polymerizable by ringopening and ringopening metathesis mechanisms, e-Polymers, 2002, 034, 1-12.

[64] Agarwal, S. Chemistry, chances and limitations of the radical ringopening polymerization of cyclic ketene acetals for the synthesis of degradable polyesters. Polym. Chem., 2010, 1, 953-964.

[65] Nuyken, O.; Pask, S.D. Ring-opening polymerization - an introductory review. Polymers, 2013, 5, 361-403.

[66] Endo, T.; Sudo, A. Radical ring-opening polymerization: molecular designs, polymerization mechanisms, and living/controlled systems. In: Controlled radical polymerization: mechanisms; Matyjaszewski, K.; Sumerlin, B.S.; Tsarevsky, N.V.; Chiefari, J., Eds; ACS Symposium Series, 2015; Vol. 1187, Chapter 2, pp. 19 50

[67] Hilf, S.; Kilbinger, A.F.M. Functional end groups for polymers prepared using ring-opening metathesis polymerization. Nat. Chem., 2009, 1, 537-546.

[68] Arslan, H. Block and graft copolymerization by controlled/living radical polymerization methods, polymerization. In: Polymerization. De Souza Gomes, A., Ed.; InTech, 2012. http://www.intechopen.com/books/polymerization/block-and-graftcopolymerization-by-controlled-living-radical-polymerizationmethods (Accessed February 12, 2016)

[69] Coelho, J.F.; Ferreira, P.C.; Alves, P.; Cordeiro, R.; Fonseca, A.C.; Góis, J.R.; Gil, M.H. Drug delivery systems: Advanced technologies potentially applicable in personalized treatments. EPMA J., 2010, 1(1), 164-209.

[70] Couffin, A.; Martín-Vaca, B.; Bourissou, D.; Navarro, C. Selective $\mathrm{O}$-acyl ring-opening of b-butyrolactone catalyzed by trifluoromethane sulfonic acid: application to the preparation of well-defined block copolymers. Polym. Chem., 2014, 5, 161-168.

[71] Kowalczuk, M.; Adamus, G.; Sikorska, W.; Rydz, J. Structural studies of biorelated polymers derived from natural PHA and their synthetic analogues with the aid of electrospray multistage mass spectrometry. Polym. Prepr. (Am. Chem. Soc., Div. Polym. Chem.), 2000, 41(2), 1626-1627.

[72] Shuai, X.; Jedlinski, Z.; Kowalczuk, M.; Rydz, J.; Tan, H Enzymatic synthesis of polyesters from hydroxyl acids. Eur. Polym. J., 1999, 35(4), 721-725.

[73] Arkin, Z.G.; Rydz, J.; Adamus, G.; Kowalczuk, M. Water-soluble L-alanine and related oligopeptide conjugates with poly[(R,S)-3hydroxybutanoic acid] oligomers. Synthesis and structural studies by means of electrospray ionization multistage mass spectrometry. J. Biomater. Sci. Polym. Ed., 2001, 12(3), 297-305.

[74] Jedliński, Z.; Kowalczuk, M.; Adamus, G.; Sikorska, W.; Rydz, J. Novel synthesis of functionalized poly(3-hydroxybutanoic acid) and its copolymers Int. J. Biol. Macromol., 1999, 25(1-3), 247-253.

[75] Kowalczuk, M. Anionic ring-opening polymerization for synthetic analogues of aliphatic biopolyesters. Polym Sci Series. A., 2009, 51, 1229-1232.

[76] Kowalczuk, M.; Adamus, G. Mass spectrometry for the elucidation of the subtle molecular structure of biodegradable polymers and their degradation products. Mass Spectrom. Rev., 2016, 35, 188198.

[77] Kudo, H.; Nishikubo, T. Catalytic reactions of oxetanes with protonic reagents and aprotic reagents leading to novel polymers. $J$. Polym. Sci. Part A: Polym. Chem., 2007, 45(5), 709-726.

[78] Barbaud, C.; Abdillah, F.; Fay, F.; Guerrouache, M.; Guerin, P. Synthesis of new $\alpha, \alpha^{\prime}, \beta$-trisubstituted $\beta$-lactones as monomers for hydrolyzable polyesters. Design. Monom. Polym., 2003, 6, 353367.

[79] Kilbinger, A.F. Developing new methods for the mono-end functionalization of living ring opening metathesis polymers. Chimia (Aarau), 2012, 66(3), 99-103.

[80] Madkour, A.E.; Koch, A.H.R.; Lienkamp, K.; Tew, G.N. Endfunctionalized ROMP polymers for biomedical applications. Macromolecules, 2010, 43(10), 4557-4561.

[81] Hilf, S.; Kilbinger, A.FM. Heterotelechelic ring-opening metathesis polymers. Macromolecules, 2010, 43, 208-212.

[82] Park, J.; Jang, S.; Kim, J.K. Morphology and microphase separation of star copolymers. J. Polym. Sci. B Polym. Phys., 2015, 53(1), 1-21. 
[83] Segalman, R.A. Patterning with block copolymer thin films. Mat. Sci. Eng. R, 2005, 48, 191-226.

[84] Vert, M. Biomedical polymers from chiral lactides and functional lactones: Properties and applications. Makromol. Chem. Macromol. Symp., 1986, 6, 109-122.

[85] Kricheldorf, H. R.; Jonte, J. M. New polymer syntheses. 8. Synthesis and polymerization of L-pactic acid O-carboxyanhydride (5-methyl-dioxolan-2,4-dione). Polym. Bull., 1983, 9, 276-283.

[86] du Boullay, O. T.; Marchal, E.; Martín -Vaca, B.; Cossio, F. P.; Bourissou, D. An activated equivalent of lactide toward organocatalytic ring-opening polymerization. J. Am. Chem. Soc., 2006, 128, 16442-16443.

[87] Martín-Vaca, B.; Bourissou, D. O-Carboxyanhydrides: useful tools for the preparation of well-defined functionalized polyesters. ACS Macro Lett., 2015, 4 (7), 792-798.

[88] Bonduelle, C.; Martín -Vaca, B.; Bourissou, D. Lipase-catalyzed ring-opening polymerization of the o-carboxylic anhydride derived from lactic acid. Biomacromolecules, 2009, 10, 3069-3073.

[89] He, Z.; Jiang, L.; Chuan, Y.; Li, H.; Yuan, M. Ring-opening polymerization of L-lactic acid O-carboxyanhydrides initiated by alkoxy rare earth compounds. Molecules, 2013, 18, 12768-12776.

[90] Yin Q.; Yin L.; Wang H.; Cheng J. Synthesis and biomedical applications of functional poly( $\alpha$-hydroxy acids) via ring-opening polymerization of O-carboxyanhydrides. Acc. Chem. Res., 2015, 48(7), 1777-1787.

[91] du Boullay, O. T.; Bonduelle, C.; Martín-Vaca, B.; Bourissou, D. Functionalized polyesters from organocatalyzed ROP of gluOCA, the O-carboxyanhydride derived from glutamic acid. Chem. Commun., 2008, 1786-1788.

[92] Yin, Q.; Tong, R.; Xu, Y. X.; Baek, K.; Dobrucki, L. W.; Fan, T. M.; Cheng, J. J. Drug-initiated ring-opening polymerization of Ocarboxyanhydrides for the preparation of anticancer drug-poly(ocarboxyanhydride) nanoconjugates. Biomacromolecules, 2013, 14, 920-929.

[93] Neugebauer, D.; Rydz, J.; Goebel, I.; Dacko, P.; Kowalczuk, M. Synthesis of graft copolymers containing biodegradable poly(3hydroxybutyrate) chains. Macromolecules, 2007, 40, 1767-1773.

[94] Koseva, N.S.; Novakov, Ch.P.; Rydz, J.; Kurcok, P.; Kowalczuk, M. Synthesis of aPHB-PEG brush co-polymers through ATRP in a macroinitiator-macromonomer feed system and their characterization. Des. Monomers Polym., 2010, 13, 579-595.

[95] Lo Verso, F.; Likos, C.N. End-functionalized polymers: Versatile building blocks for soft materials. Polymer, 2008, 49, 1425-1434.

[96] Danko, M.; Libiszowski, J.; Biela, T,; Wolszczak, M.; Duda, A. Molecular dynamics of star-shaped poly(L-lactide)s in tetrahydrofuran as solvent monitored by fluorescence spectroscopy. J. Polym. Sci. Part A Polym. Chem., 2005, 19, 4586-99.

[97] Kricheldorf, H.R.; Thiessen, H.H. Telechelic polylactones functionalized with trimethoxysilyl groups. Polymer, 2005, 46, 12103-8.

[98] Hartmann, R.; Hany, R.; Geiger, T.; Egli, T.; Witholt, B.; Zinn, M. Tailored biosynthesis of olefinic medium-chain-length poly [(R)-3hydroxyalkanoates] in Pseudomonas putida GPo1 with improved thermal properties. Macromolecules, 2004, 37(18), 6780-6785.

[99] Kim, do Y.; Kim, H.W.; Chung, M.G.; Rhee, Y.H. Biosynthesis, modification, and biodegradation of bacterial medium-chain-length polyhydroxyalkanoates. J. Microbiol., 2007, 45(2), 87-97.

[100] Hany, R.; Böhlen, C.; Geiger, T.; Schmid, M.; Zinn, M. Toward non-toxic antifouling: Synthesis of hydroxy-, cinnamic acid-, sulfate-, and zosteric acid-labeled poly [3-hydroxyalkanoates]. Biomacromolecules, 2004, 5(4), 1452-1456.

[101] Lee, M.Y.; Park, W.H.; Lenz, R.W. Hydrophilic bacterial polyesters modified with pendant hydroxyl groups. Polymer, 2000, 41(5), 1703-1709.

[102] de Roo, G.; Kellerhals, M. B.; Ren, Q.; Witholt, B.; Kessler, B. Production of chiral R-3-hydroxyalkanoic acids and R-3hydroxyalkanoic acid methylesters via hydrolytic degradation of polyhydroxyalkanoate synthesized by pseudomonads. Biotechnol. Bioeng. 2002, 77, 717-722.

[103] Ren, Q.; Ruth, K.; Thöny-Meyer, L.; Zinn, M. Enatiomerically pure hydroxycarboxylic acids: current approaches and future perspectives. Appl. Microbiol. Biotechnol., 2010, 87(1), 41-52.

[104] Andrade, A.P.; Neuenschwander, P.; Hany, R.; Egli, T.; Witholt, B.; Li, Z. Synthesis and characterization of novel copoly(esterurethane) containing blocks of poly-[(R)-3-hydroxyoctanoate $]$ and poly-[(R)-3-hydroxybutyrate]. Macromolecules, 2002, 35, 49464950 .
[105] Hartmann, R. Tailored medium-chain-length poly[(R)-3hydroxyalkanoates]: biosynthetic and chemical approaches. $\mathrm{PhD}$ Thesis, Swiss Federal Institute of Technology Zurich, Switzerland, 2005.

[106] Häberlein, H.; Seliger, H.; Kohler, R.; Sulzberger, P. Cost-effective synthesis of environmentally benign materials on the basis of poly3-hydroxybutyrate. Polímeros, 2005, 15(2), 122-126.

[107] Saad, G. R.; Seliger, H. Biodegradable copolymers based on bacterial Poly ((R)-3-hydroxybutyrate): thermal and mechanical properties and biodegradation behaviour. Polym. Degrad. Stab., 2004, 83(1), 101-110.

[108] Choi, K.Y. Overview on polymerization reactor technology. In: Handbook of polymer science and technology; Cheremisinoff, N.P. Ed.; CRC Press: New York, US, 1989; Tom 1, pp. 67-102.

[109] Kucharczyk, P.; Poljansek, I.; Sedlarik, V.; Kasparkova, V.; Salakova, A.; Drbohlav, J.; Cvelbar, U.; Saha P. Functionalization of polylactic acid through direct melt polycondensation in the presence of tricarboxylic acid. J. Appl. Polym. Sci., 2011, 122, 1275-1285.

[110] Bikiaris, D.N.; Achilias, D.S. Synthesis of poly(alkylene succinate) biodegradable polyesters, Part II: Mathematical modelling of the polycondensation reaction. Polymer, 2008, 49, 3677-3685.

[111] You, Z.; Cao, H.; Gao, J.; Shin, P.H.; Day, B.W.; Wang, Y. A functionalizable polyester with free hydroxyl groups and tunable physiochemical and biological properties. Biomaterials, 2010, 31(12), 3129-3138.

[112] Kline, B.K.; Beckman, E.J.; Russell, A.J. One-step biocatalytic synthesis of linear polyesters with pendant hydroxyl groups. J. Am. Chem. Soc., 1998, 120, 9475-9480.

[113] Nagata, M. Synthesis and enzymatic degradation of poly(esteramide) stereocopolymers derived from alanine. Macromol. Chem. Phys., 1999, 200(9), 2059-2064.

[114] Zinck, P. Synthetic strategies for biomedical polyesters specialties, In: Biomedical engineering, trends in materials science; Laskovski A., Ed.; InTech, Croatia, 2011; pp. 489-512.

[115] Uyama H.; Inada K.; Kobayashi S. Regioselectivity control in lipase-catalyzed polymerization of divinyl sebacate and triols. Macromol. Biosci., 2003, 1, 40-44.

[116] Kumar, A.; Kulshresta, S.; Gao, W.; Gross, R.A. Versatile route to polyol polyesters by lipase catalysis. Macromolecules, 2003, 36, 8219-8221.

[117] Mallakpour, S.; Zeraatpisheh, F.; Sabzalian, M.R. Construction, characterization and biological activity of chiral and thermally stable nanostructured poly(ester-imide)s as tyrosine-containing pseudo-poly(amino acid)s. J. Polym. Environ., 2012, 20, 117-123.

[118] Rodriguez-Galan, A.; Franco, L.; Puiggali, J. Degradable poly(ester amide)s for biomedical applications, Polymers, 2011, 3, 65-99.

[119] Jaszcz, K.; Lukaszczyk, J.; Smiga-Matuszowicz, M. Synthesis of functional poly(ester anhydride)s based on succinic acid. React. Funct. Polym., 2008, 68, 351-360.

[120] Santerre, J.P.; Woodhouse, K.; Laroche, G.; Labow, R.S. Understanding the biodegradation of polyurethanes: From classical implants to tissue engineering materials. Biomaterials, 2005, 26, 7457-7470.

[121] Ferruti, P.; Marchisio, M.A.; Duncan, R. Poly(amido-amine)s: biomedical applications. Macromol. Rapid Commun., 2002, 23, 332-355.

[122] Tabujew, I.; Peneva, K. Functionalization of cationic polymers for drug delivery applications, In: Cationic polymers in regenerative medicine, Samal S. K.; Dubruel, P., Eds. 2014; pp. 1-29.

[123] Fenili, F.; Manfredi, A.; Ranucci, E.; Ferruti, P. Poly(amidoamine) hydrogels as scaffolds for cell culturing and conduits for peripheral nerve regeneration. Int. J. Polym. Sci., 2011, Article ID 161749, 20 pages.

[124] Ekenseair, A.K.; Boere, K.W.M.; Tzouanas, S.N.; Vo, T.N.; Kasper, F.K.; Mikos, A.G. Synthesis and characterization of thermally and chemically gelling injectable hydrogels for tissue engineering Biomacromolecules, 2012, 13, 1908-1915.

[125] Butsele, K.V.; Jerome, R.; Jerome, C. Functional amphiphilic and biodegradable copolymers for intravenous vectorisation. Polymer, 2007, 48, 7431-7443.

[126] Hashimoto, K.; Okada, M.; Honjou N. Ring-opening polyaddition of D-glucaro-1,4:6,3-dilactone with p-xylylenediamine, Makromol. Chem. Rapid Comm., 1990, 8, 393-396.

[127] Dong, B.; Li, Z.; Zhang, L.; Du, F.; Li, Z. Synthesis of linear functionalized polyesters by controlled atom transfer radical polyaddition reactions. Polym. Chem., 2012, 3, 2523-2530. 
[128] Deng, X.; Zheng, N.; Song, Z.; Yin, L.; Cheng, J. Triggerresponsive, fast-degradable poly(b-amino ester)s forenhanced DNA unpackaging and reduced toxicity . Biomaterials, 2014, 35, 50065015.

[129] Chen, J.; Huang, S.; Liu, M.; Zhuo, R. Synthesis and degradation of poly(beta-aminoester) with pendant primary amine. Polymer, 2007, $48,675-681$. 